\title{
Investigation of wheelchair instability during transport in large accessible transit vehicles
}

\author{
Zdravko Salipur, MEng; Karen Frost, PhD; Gina Bertocci, PhD, PE \\ Injury Risk Assessment and Prevention (iRAP) Laboratory, Mechanical Engineering Department, J. B. Speed School of \\ Engineering, University of Louisville, Louisville, $K Y$
}

\begin{abstract}
Large accessible transit vehicles (LATVs, fixedroute intracity buses), generally considered safe, may not be as safe for wheelchair-seated passengers. Transit provider practices vary regarding use of wheelchair tiedown and occupant restraint systems (WTORSs), while recent research suggests high levels of WTORS disuse and misuse. We sought to better understand wheelchair and wheelchair passenger instabilities related to WTORS disuse and misuse on LATVs. This article presents a retrospective review of 295 video surveillance records of wheelchair passenger trips on LATVs. Wheelchair trips involving disuse and misuse of WTORS were quantified and categorized based on WTORS configurations. Cases of wheelchair and wheelchair passenger instability were categorized based on severity, type, and direction. Three adverse events involving severe wheelchair and/or passenger instability were examined in greater detail. Results showed $20.3 \%$ of records involved wheelchair-related adverse events (95\% minor instabilities, 5\% severe instabilities). Scooters were most likely to be unstable, followed by manual and power wheelchairs. In most instability cases, no tiedowns were used to secure the wheelchair and no lap belt was used to restrain the wheelchair passenger properly. In many instances, the lap belt was misused in an attempt to secure the wheelchair, whereas the shoulder belt was never used.
\end{abstract}

Key words: Americans with Disabilities Act, fixed-route intracity bus, instability, large accessible transit vehicle, public transit, wheelchair instability, wheelchair safety, wheelchair securement, wheelchair tiedown and occupant restraint system, wheelchair transportation.

\section{INTRODUCTION}

Large accessible transit vehicles (LATVs), commonly known as fixed-route intracity buses, are generally considered a safe mode of transportation with a low fatality incidence of all passengers [1]. This is in part because of overall LATV mass and the slow speed of travel associated with intracity routes. Despite this relatively safe environment, Shaw and Gillispie found that wheelchair passengers have an accident rate over 350 times greater than that of non-wheelchair-using passengers [2]. Shaw estimated that the ratio of wheelchair passenger injury claims relative to the wheelchair passenger population is much higher than the claims ratio for the general population, indicating a higher likelihood for wheelchair passengers to incur injuries [3]. The U.S. National Highway Transportation Safety Administration reported that 35 percent of injuries and deaths that occurred between 1990 and 1995 involving

\footnotetext{
Abbreviations: $\mathrm{ADA}=$ Americans with Disabilities Act, $\mathrm{CG}=$ center of gravity, ISO = International Organization for Standardization, LATV = large accessible transit vehicle, NIDRR = National Institute on Disability and Rehabilitation Research, ORS = occupant restraint system, WoFT = Wheelchairs on Fixed-Route Transit, WTORS = wheelchair tiedown and occupant restraint system.

*Address all correspondence to Gina Bertocci, PhD, PE; University of Louisville, Research Tower, Room 204, 500 S. Preston St, Louisville, KY 40202; 502-852-0296; fax: 502852-6053. Email: g.bertocci@louisville.edu

http://dx.doi.org/10.1682/JRRD.2011.06.0098
} 
wheelchair users were because of improper or no securement of the wheelchair, and 17 percent of these incidents occurred in LATVs [4].

In general, it is recommended that wheelchair passengers transfer to a vehicle seat, provided they have adequate postural stability and the opportunity to utilize an occupant restraint system (ORS). However, the vast majority of surveyed wheelchair passengers (85\%) remain seated in their wheelchairs during transit, which may put them at increased risk of injury [5]. Songer et al. found that passengers who remained seated in their wheelchairs during transit experienced higher injury rates (5.2 passenger injuries per 100,000 miles) than those who transferred to a motor vehicle seat ( 0.6 passenger injuries per 100,000 miles) [6].

It is necessary to afford wheelchair passengers the same level of transportation safety as the general population. The Americans with Disabilities Act (ADA) requires that LATVs be equipped with a wheelchair securement device and lap and shoulder belts [7]. A common method to secure the wheelchair and restrain the wheelchair occupant is using the four-point, strap-type wheelchair tiedown and occupant restraint system (WTORS). The correct use of such WTORS depends on two components. First, the wheelchair should be secured using four tiedown straps attached at appropriate securement points on the wheelchair. Two tiedowns attach to the front of the wheelchair and two to the rear of the wheelchair. Second, the wheelchair passenger should be restrained with the lap and shoulder belts so that they make contact with the anterior of the pelvis near the upper thighs and with the shoulder and chest, respectively [8]. Although the ADA requires the provision of a wheelchair securement device and ORS (lap and shoulder belts), it does not mandate the use of such systems [9]. Individual transit agencies are left to establish policies requiring the use of wheelchair tiedowns. Additionally, the ADA does not require mandatory use of lap and/or shoulder belt restraints for wheelchair-seated passengers unless the same mandate has been made for the general ridership [9]. As a result, there are disparities between transit agency policies with respect to WTORS use [5].

"Disuse" and "misuse" of WTORS has been shown to place wheelchair-seated passengers at greater risk of injury. Shaw and Gillispie identified misuse as a factor contributing to wheelchair passenger injuries [2]. Frost and Bertocci reviewed video surveillance records of WTORS usage on LATVs and found that the majority
(76\%) of wheelchairs were not secured using four-point strap-type tiedowns during transport and that misuse of the lap belt was common (44\% of cases) [10]. Misuse of the lap belt often consisted of the LATV operators attempting to secure the wheelchair by routing the lap belt around the wheelchair seatback in an attempt to secure the wheelchair. Wolf et al. also observed WTORS use on LATVs and reported incomplete utilization of available securement systems in 62 percent of observations and no observations of ORS use [11].

This article presents a comprehensive review of videorecorded, wheelchair-related "adverse events" involving disuse and misuse of WTORS during transit, identifying WTORS configurations associated with adverse wheelchair and passenger outcomes. We examine three adverse events involving severe wheelchair and/or wheelchairseated passenger instability while traveling in an LATV in greater detail.

\section{METHODS}

In a separate study, Frost and Bertocci reviewed invehicle digital video surveillance footage of wheelchair activities in LATVs archived during the 21-month period between June 2007 and February 2009 [10]. The transit agency provided randomly selected digital video recorders containing video footage. Video footage of wheelchair trips (ingress through egress) were captured and archived for analysis in the Wheelchairs on Fixed-Route Transit (WoFT) database. Individual wheelchair passengers were not identified and so could, theoretically, be represented in multiple trips or events. The WoFT database includes information such as the number of tie-downs and occupant restraints used, wheelchair type, time required to secure the wheelchair, whether wheelchair-related instability occurred during transit, and various other parameters relevant to wheelchair transit. Of the 285 LATVs operated by the transit agency, 60 were equipped with the MobileView III video surveillance system (GE Security, United Technologies Corporation; Hartford, Connecticut). This system records digital video images at a frequency of 30 frames per second with up to $640 \times 480$ pixel resolution. Each invehicle video surveillance system consists of four to six permanently mounted video cameras (Figure 1). Typically, each LATV was equipped with cameras to include views from the front windshield, front and rear of the LATV interior, and front and rear doors, as well as the wheelchair 


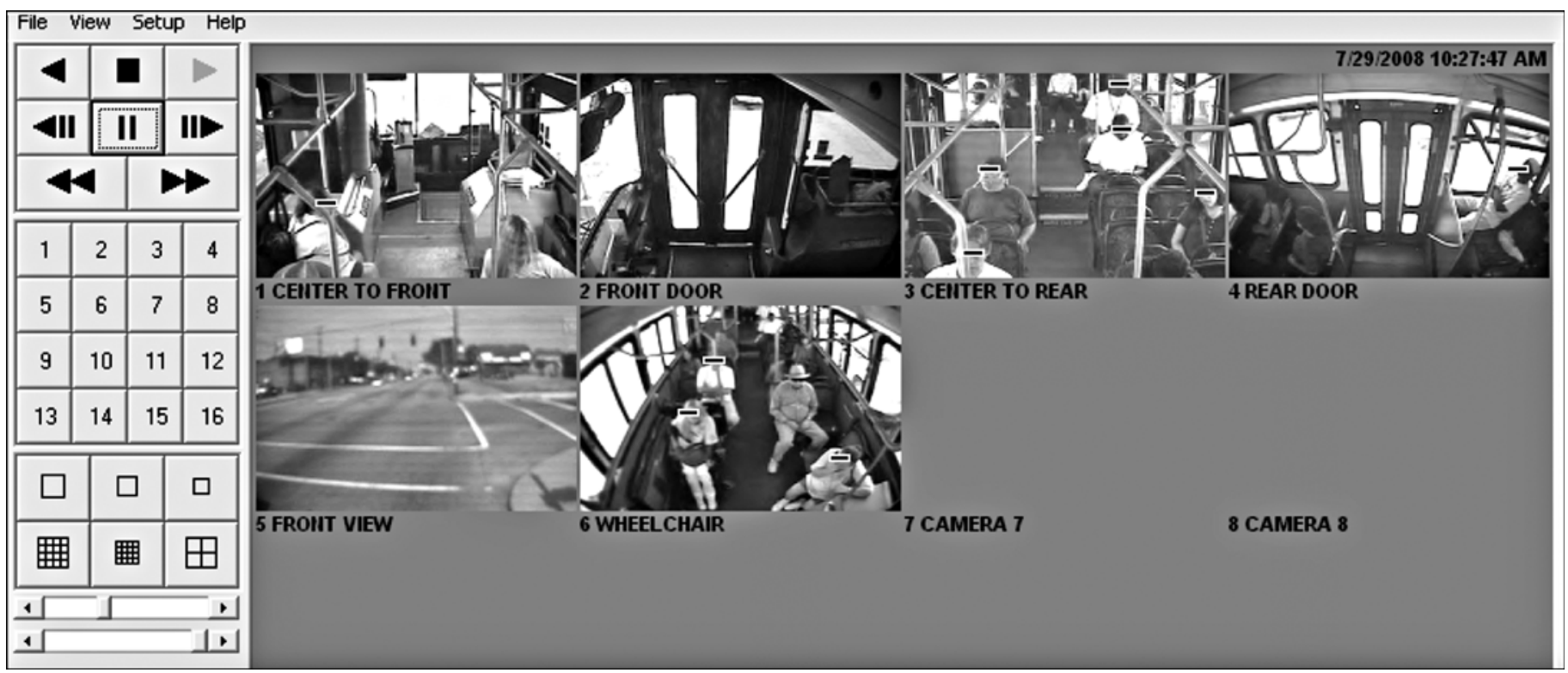

Figure 1.

In-vehicle six-camera large accessible transit vehicle (LATV) video surveillance system. This LATV was equipped with cameras to include views from front windshield, front and rear of interior, and front and rear doors, as well as wheelchair securement station.

securement station. We used the views of the wheelchair securement station and front of the LATV interior most often to observe events. Additional information describing the video collection process is published elsewhere [10].

The WoFT database contains 295 records. Each record corresponds to a single video file of one wheelchair-seated passenger trip. For this article, we filtered records to extract a subset of adverse events involving wheelchairs and/or wheelchair passengers. We defined an adverse event as any event involving wheelchair and/or wheelchair passenger instability during transit. Because of the low resolution and low frequency of the video data, excursions could not be quantified, and we qualitatively categorized adverse events into two categories: "minor" or "severe" instability. We defined minor instability as wheelchair excursions when the wheelchair remained within the securement station. We defined severe instability as wheelchair excursions that exceeded the boundary of the securement station into the aisle and/ or wheelchair passenger ejection from their wheelchair.

We also characterized adverse events based on wheelchair type, direction of excursion (fore-aft wheelchair excursion, lateral wheelchair excursion, combined fore-aft and lateral wheelchair excursion, and other wheelchair and/or wheelchair passenger excursion), and WTORS configuration (number of tiedowns applied and whether the lap belt and shoulder belt were used). We used two terms to categorize ORS usage: disuse was a situation in which neither the shoulder nor lap belt was used, and misuse was improper implementation of the lap and/or shoulder belt. Note: whether or not appropriate lap and/or shoulder belt fit on the passenger was achieved could not be determined because of limited video camera resolution and view angles.

For this article, we reviewed cases involving severe instability in greater detail, noting responsive actions taken by the wheelchair passenger, LATV operator, and/ or other passengers. Additionally, we described dynamics of the wheelchair and/or wheelchair passenger along with the dynamics of the other passengers and the LATV driving conditions. We used descriptive statistics to characterize adverse events (PASW Statistics, version 17, SAS Inc; Cary, North Carolina) based on assessed variables.

\section{RESULTS}

\section{Wheelchair Instability Based on Wheelchair Type}

We identified 60 records (20.3\%) meeting the criteria of an adverse event involving wheelchair and/or wheelchair passenger instability during transit from the WoFT database (Table 1). Of these 60 adverse events, we 
JRRD, Volume 49, Number 6, 2012

Table 1.

Proportion of instability cases by wheelchair type in Wheelchairs on Fixed-Route Transit database.

\begin{tabular}{lcccc}
\hline Wheelchair Type & $\begin{array}{c}\text { Total Wheelchair Trips } \\
(\boldsymbol{n}=\mathbf{2 9 5 )}\end{array}$ & $\begin{array}{c}\text { Proportion of All } \\
\text { Wheelchair Trips } \\
(\mathbf{\%})\end{array}$ & $\begin{array}{c}\text { Total Instability Cases } \\
(\boldsymbol{n}=\mathbf{6 0 )}\end{array}$ & $\begin{array}{c}\text { Proportion of Instability } \\
\text { Cases (Minor and Severe) } \\
(\mathbf{\%})\end{array}$ \\
\hline Power & 202 & 68.5 & 31 & 15.3 \\
Manual & 74 & 25.1 & 22 & 30.1 \\
Scooter & 19 & 6.4 & 7 & 36.8 \\
\hline \hline
\end{tabular}

categorized 57 cases (95\%) as minor instability, while we identified 3 cases (5\%) as severe instability. The greatest number of wheelchair instability cases involved power wheelchairs (31 cases), followed by manual wheelchairs (22 cases) and scooters (7 cases). Although a greater number of wheelchair instability cases were experienced by power wheelchairs users, the greatest proportion of wheelchair instability cases relative to the number of trips for a specific wheelchair type were experienced by scooter users (36.8\%; 7 of 19 records). For manual wheelchair users, the proportion was 30.1 percent (22 of 73 records), and for power wheelchairs, the proportion was 15.3 percent (31 of 202 records).

\section{Minor Wheelchair Instability Cases}

The tree-diagram in Figure 2 characterizes the direction of excursion and WTORS configuration for each adverse event with minor instability. The second level of the tree diagram indicates the distribution based on direc- tion of excursion. The third level indicates number of tiedowns used, and the fourth level indicates how the ORS was applied. Of the 57 events of minor instability, 25 (43.9\%) involved a combination of fore/aft and lateral excursions of the wheelchair, while 22 (38.6\%) involved fore/aft excursions only. We associated eight events (14.0\%) with lateral excursions only and categorized two events (3.5\%) as other wheelchair and/or wheelchair passenger instability (e.g., rear wheels of wheelchair lifting off ground, wheelchair passenger driving wheelchair out of securement station during LATV transit). For all subcategories, the most frequent number of wheelchair tiedowns used was zero; 20 of 25 events (80\%) involved fore/aft and lateral excursions, 18 of 22 events (82\%) involved fore/aft excursions only, 7 of 8 events (88\%) involved lateral excursions, and 2 of 2 events (100\%) involved another instability type. Our findings also indicate minimal use of the ORS. The ORS was used to restrain the wheelchair-seated passenger in only 13 of

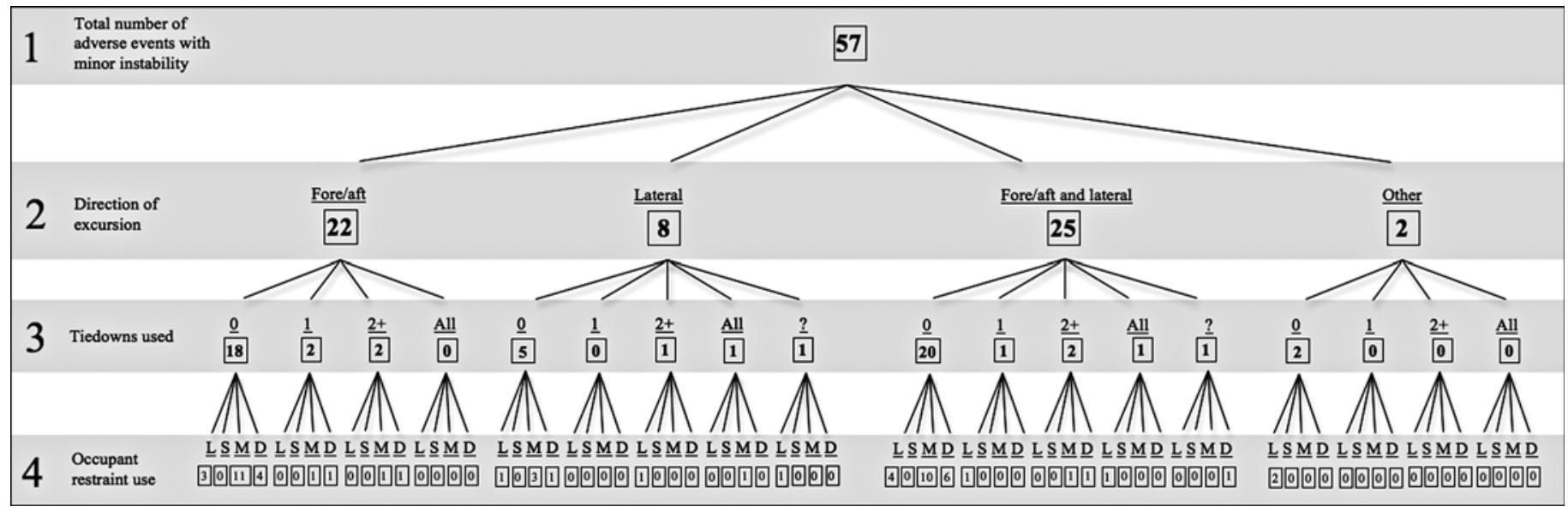

Figure 2.

Tree-diagram showing direction of excursion, number of tiedowns used, and occupant restraint system use for 57 wheelchair instability events categorized as minor instability. $D=$ occupant restraint system disuse, $L=$ lap belt used, $M=$ occupant restraint system misuse, $\mathrm{S}=$ shoulder belt used. 
57 adverse events with minor instability (22.8\%). The most frequently observed use of the ORS was the misuse of the WTORS to secure the wheelchair. Specifically, the lap belt was used to secure the wheelchair by routing the lap belt around the wheelchair seatback. We also determined the WTORS configurations by wheelchair type in all 57 cases of minor instability (Figure 3).

\section{Severe Wheelchair Instability Cases}

One manual wheelchair and two power wheelchair passengers experienced an adverse event with severe instability. Table 2 provides summary data for each case, followed by a detailed description of each.

\section{Case 1: Power Wheelchair Driven into Aisle}

A male wheelchair passenger boarded the LATV and positioned his mid-wheel-drive power wheelchair facing

(a)
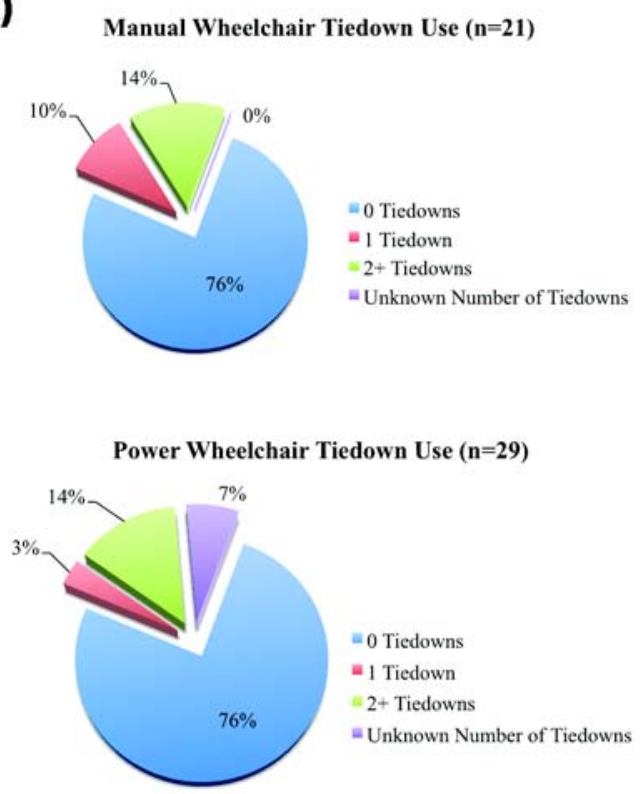

Scooter Tiedown Use $(n=7)$

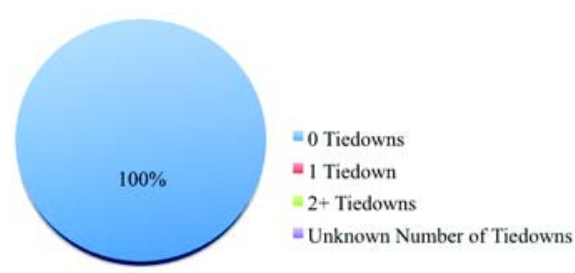

forward in the entry-door side (LATV direction of travel) securement station. An augmentative communication device was mounted to the wheelchair at the passenger's mid-torso level. Power to the wheelchair was not turned off prior to transit. The operator did not apply any tiedowns to secure the wheelchair, nor were the occupant lap and shoulder belts applied to restrain the passenger. The operator instead misused the lap belt by loosely wrapping it around the wheelchair seatback in an apparent attempt to secure the wheelchair.

The LATV appeared to be traveling at a constant forward velocity and was not turning, accelerating, or braking. Approximately 1 minute into transit, the power wheelchair appeared to rotate laterally into the aisle space (Figures 4 and 5). The wheelchair passenger remained seated in the wheelchair during this excursion. No non-wheelchair-using passengers were standing in the

(b)

Manual Wheelchair Occupant Restraint Use (n=21)

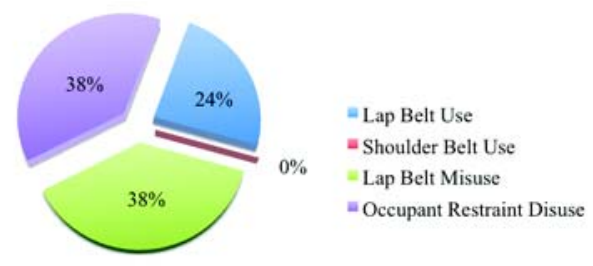

Power Wheelchair Occupant Restraint Use $(n=29)$

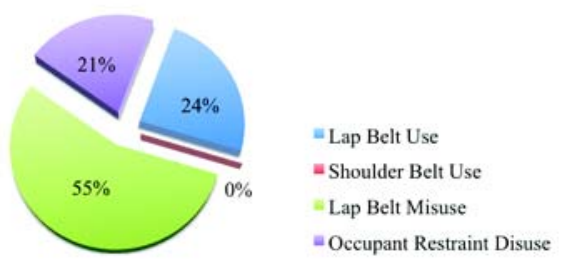

Scooter Occupant Restraint Use (n=7)

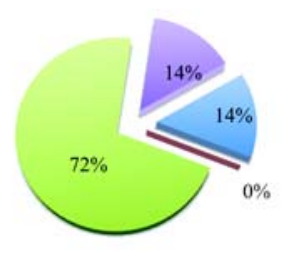

- Lap Belt Use

= Shoulder Belt Use

- Lap Belt Misuse

= Occupant Restraint Disuse

Figure 3.

(a) Tiedown and (b) occupant restraint system configurations by wheelchair type in minor instability cases. 
JRRD, Volume 49, Number 6, 2012

Table 2.

Summary data for severe large accessible transit vehicle (LATV) instability cases.

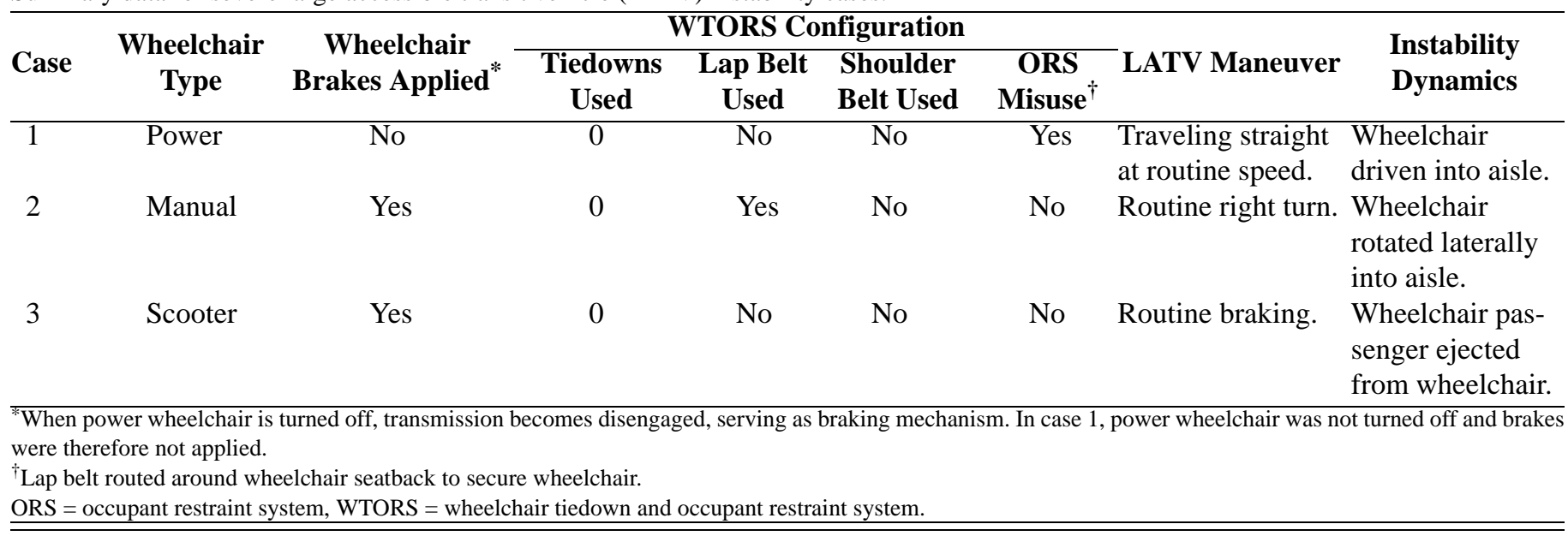

aisle during transit and no passengers were injured. A non-wheelchair-using passenger sitting across the aisle from the wheelchair passenger moved his right foot in an apparent attempt to avoid injury, and then used it to restrain the left front wheelchair footrest to prevent the wheelchair from moving farther into the aisle.

Video review revealed hand movement near the wheelchair controller immediately preceding wheelchair excursion. It appeared that the wheelchair passenger engaged the controller, causing the wheelchair to rotate into the aisle space. The LATV operator stopped en route and manually repositioned the power wheelchair in the securement station. The operator spoke with the nonwheelchair-using passenger and then appeared to turn the power to the wheelchair off. The operator again did not secure the wheelchair using tiedowns, nor did she apply

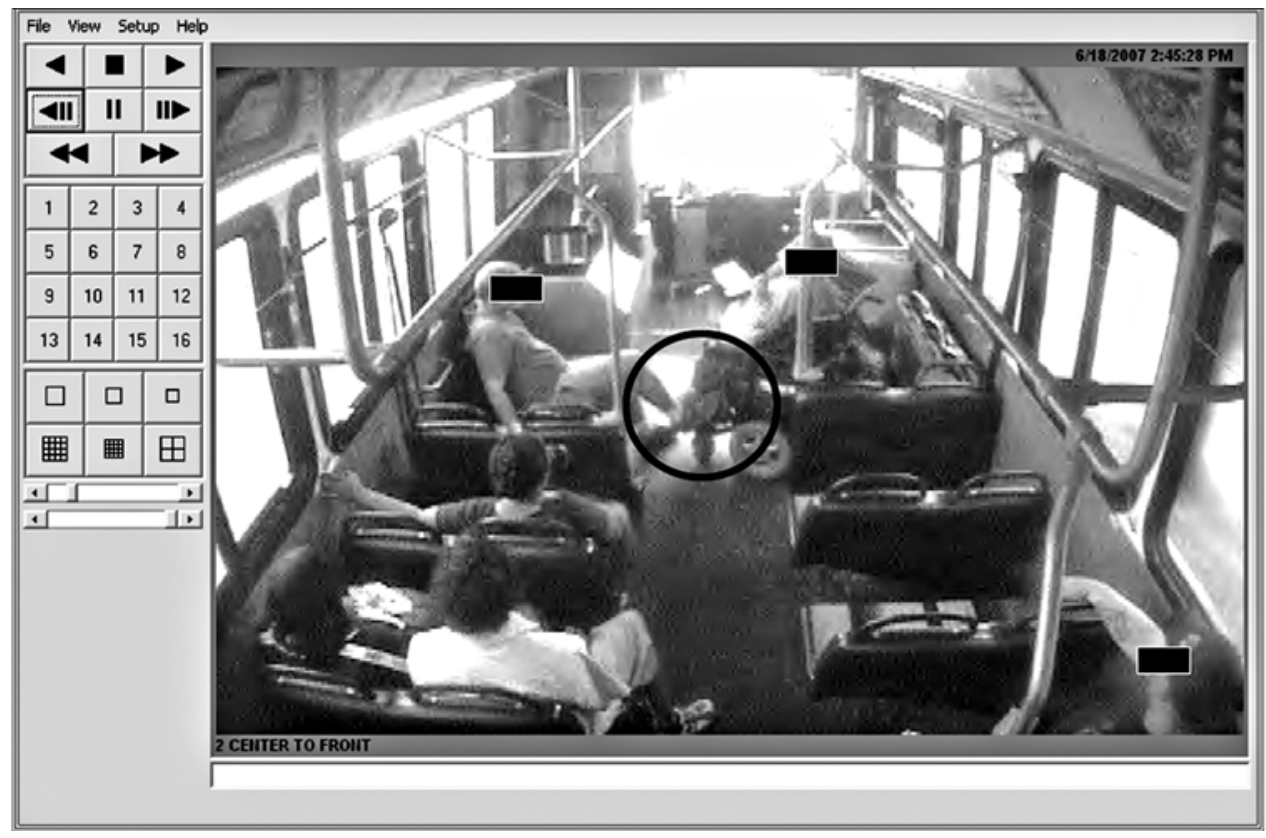

Figure 4.

Case 1: Unsecured power wheelchair enters aisle during routine large accessible transit vehicle (LATV) transit, while sitting nonwheelchair-using passenger lifts foot to prevent injury and limit power wheelchair movement. (View from LATV rear.) 


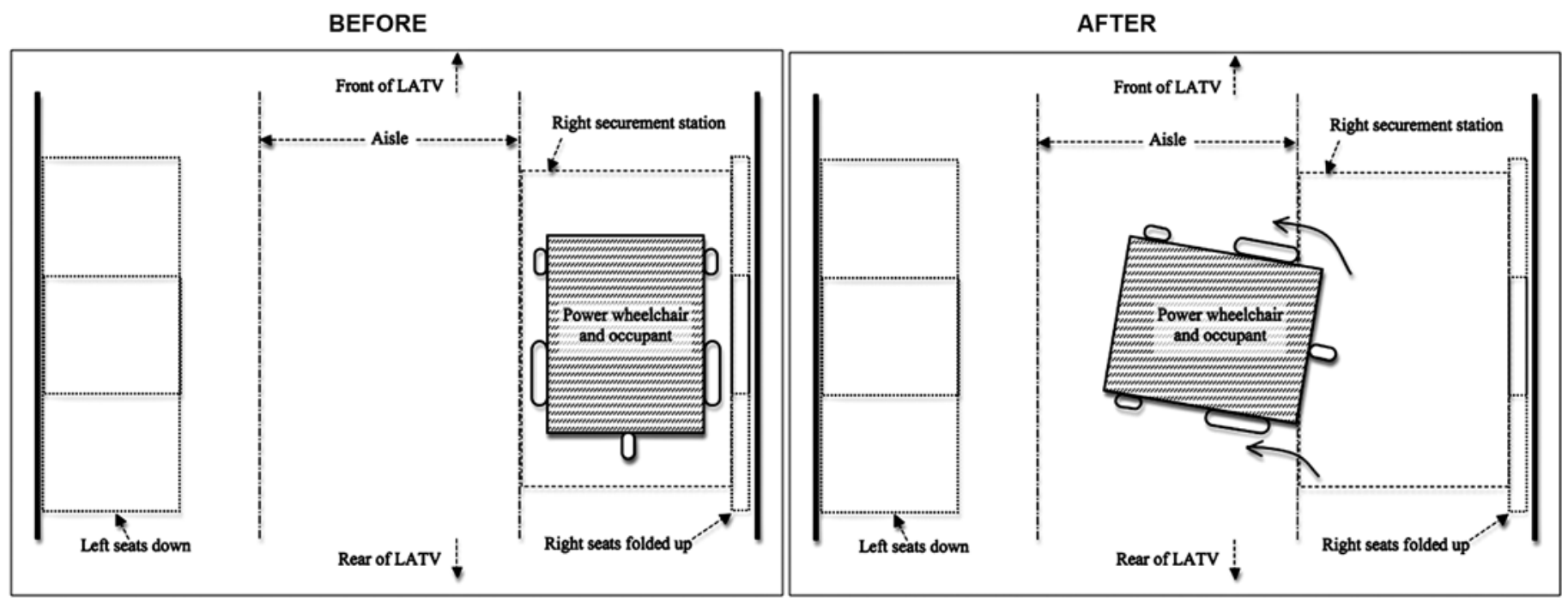

Figure 5.

Diagram showing unsecured power wheelchair rotating laterally into aisle during routine large accessible transit vehicle (LATV) transit (case 1).

the shoulder belt or tighten the lap belt, which was still loosely wrapped around the seatback. No further instability occurred during the remainder of the trip.

\section{Case 2: Manual Wheelchair Rotated Laterally into Aisle}

A male wheelchair passenger boarded the LATV, positioned his manual wheelchair forward-facing in the entry-door side securement station, and applied both brakes. The LATV operator did not apply any tiedowns to secure the wheelchair. To restrain the wheelchair passenger, the operator applied the lap belt correctly under the wheelchair armrests, albeit very loosely across the wheelchair passenger's pelvic region. The shoulder belt was not used.

Two minutes into transit, the LATV initiated a right turn. During the turn, the wheelchair rotated laterally into the aisle (Figures 6 and 7). As the wheelchair rotated into the aisle, the passenger grabbed the folding-seat under the window with his right arm and stabilized himself by placing both feet on the ground. A non-wheelchair-using passenger sitting across the aisle prevented additional excursion of the wheelchair into the aisle by extending her right leg and using her foot to push against the left rear wheel of the wheelchair. There were no passengers standing in the aisle and no passengers were injured. Immediately after the adverse event occurred, the LATV came to a stop and the wheelchair passenger repositioned his wheelchair in the securement station. Once stopped, the LATV operator returned to the securement station and secured the wheelchair using all four tiedowns; he did not apply the shoulder belt or reapply the lap belt. No further instability occurred during the remainder of the trip.

\section{Case 3: Power Wheelchair Passenger Ejected from Wheelchair}

A female wheelchair passenger boarded the LATV and positioned her power wheelchair forward-facing in the entry-door side securement station. The power wheelchair was equipped with captain seating that appeared inappropriately sized (too small) for the bariatric wheelchair passenger. The wheelchair passenger appeared to turn off power to the wheelchair. The LATV operator did not secure the wheelchair with any tiedowns and did not apply the lap or shoulder belts to restrain the occupant.

The LATV was traveling in a forward direction at apparent routine speed relative to traffic. As it approached an intersection, the LATV appeared to slow down via normal braking, and the wheelchair passenger was ejected from her wheelchair into the aisle. Video observation reveals that the wheelchair remained in position within the securement station as the LATV reduced speed. The wheelchair passenger was ejected in a forward direction from her wheelchair (Figures 8 and 9). During ejection, the wheelchair passenger attempted to stabilize herself (stop her 


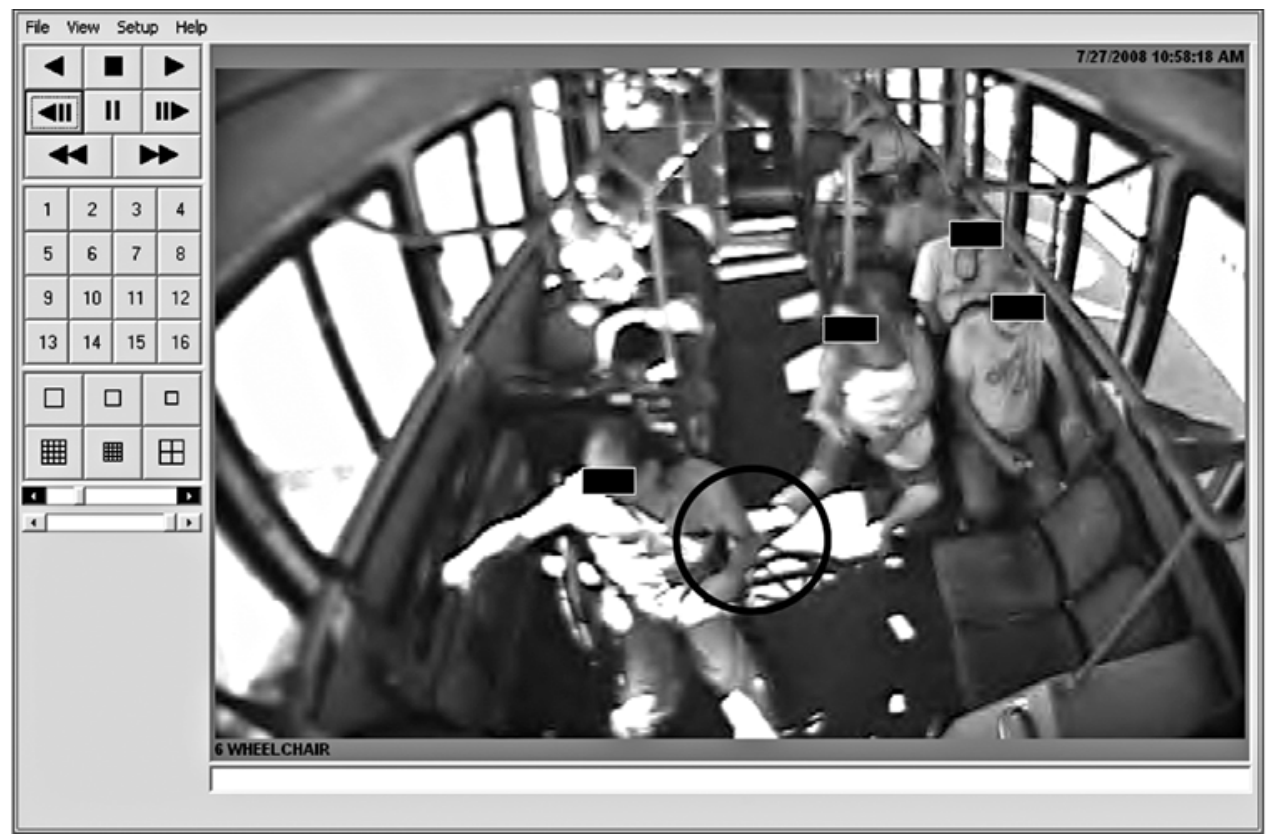

Figure 6.

Case 2: Manual wheelchair passenger and wheelchair rotated into aisle as large accessible transit vehicle (LATV) performed right turn. Wheelchair passenger stabilized himself by placing both feet on floor and using his right arm to grab folding seat while nonwheelchair-using passenger used her foot to prevent additional lateral excursion of wheelchair. (View from LATV front.)

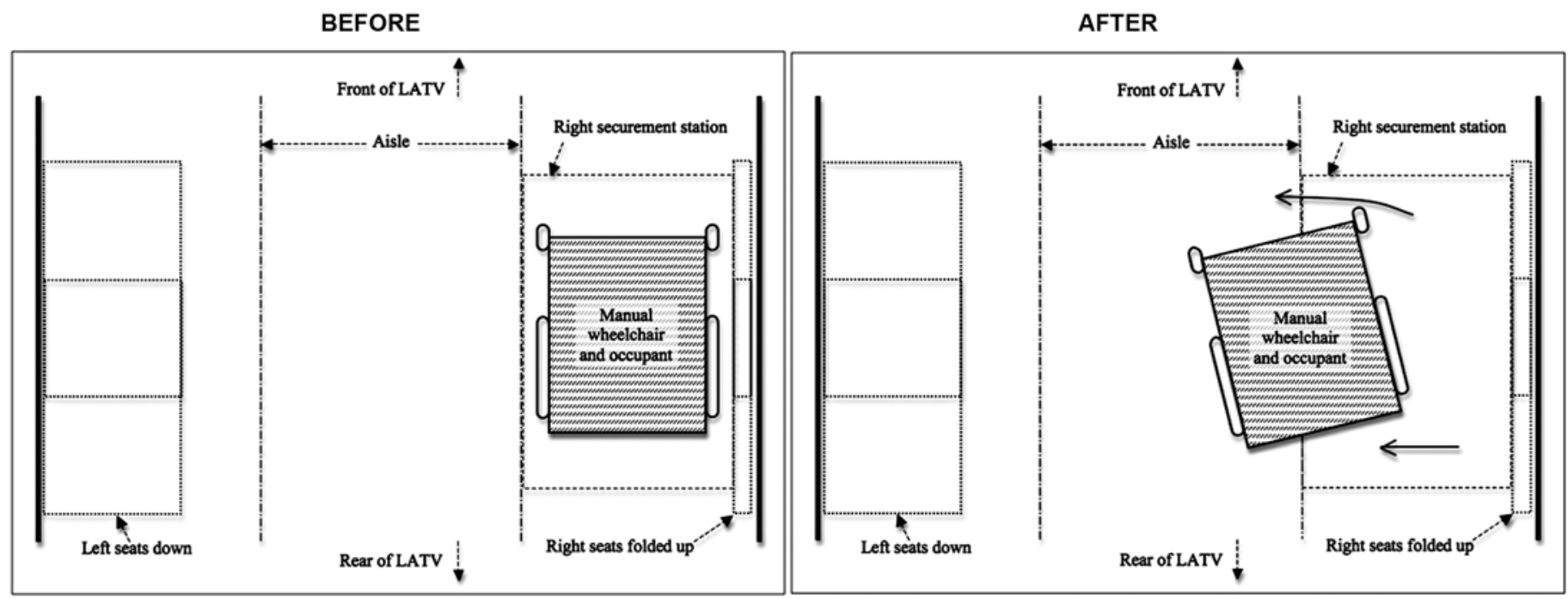

Figure 7.

Diagram showing manual wheelchair and wheelchair passenger rotating laterally into aisle during routine right turn (case 2). Note: Orientation of this diagram is $180^{\circ}$ opposite of Figure 6 camera view.

forward motion) by using her right arm to prevent impact with the LATV bulkhead directly in front of the securement station. The passenger struck the bulkhead with her lower limbs at knee level and fell laterally to the aisle floor. A non-wheelchair-using passenger sitting across the aisle attempted to restrain the wheelchair passenger with an 


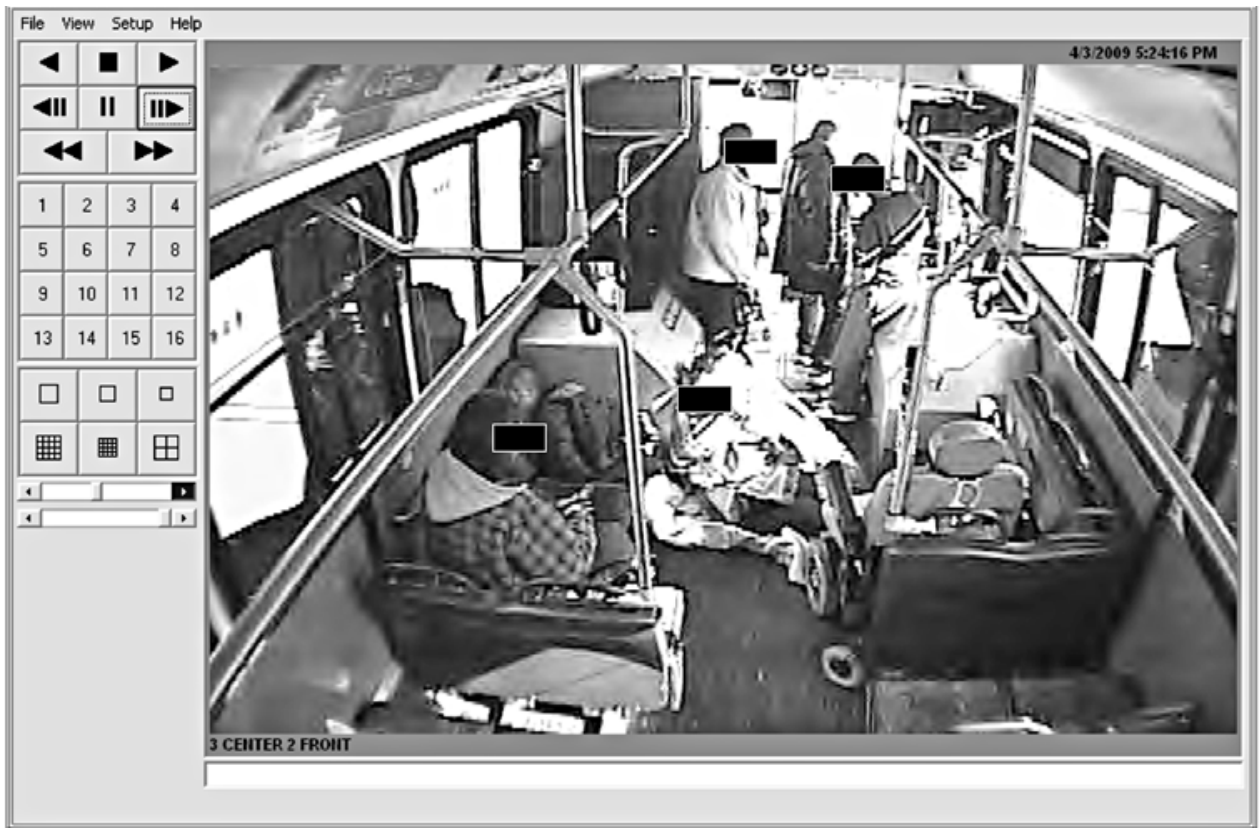

Figure 8.

Case 3: Power wheelchair passenger ejected from wheelchair during normal large accessible transit vehicle (LATV) braking. Wheelchair passenger struck bulkhead in front of securement station and fell to floor complaining of fractured leg. (View from LATV rear.)

BEFORE

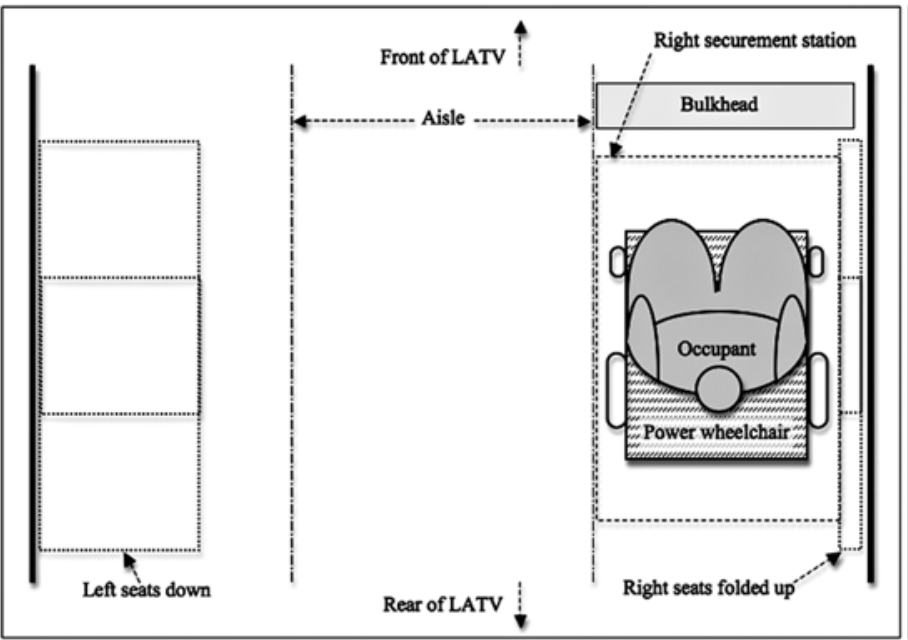

AFTER

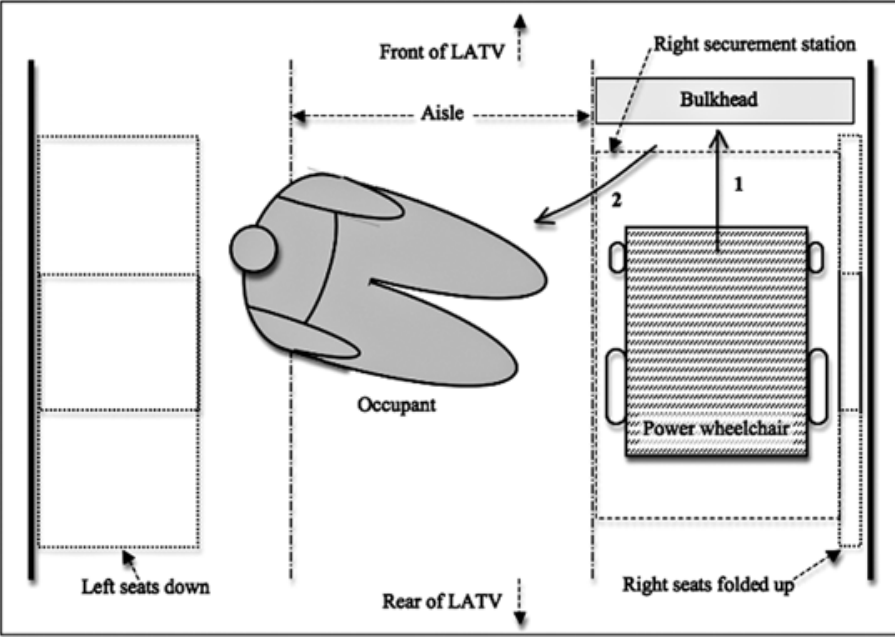

Figure 9.

Diagram showing power wheelchair passenger ejected from power wheelchair during apparent routine braking maneuver. During ejection, (1) wheelchair passenger struck large accessible transit vehicle (LATV) bulkhead directly in front of right securement station, and (2) then fell to aisle floor (case 3).

outstretched arm during her ejection and fall. There were no passengers standing in the aisle, nor were any other passengers injured.
Immediately after the adverse event occurred, the LATV came to a stop. The wheelchair passenger could be heard on the video complaining that her leg was fractured. 
Four non-wheelchair-using passengers and later emergency medical services personnel failed in an attempt to lift the injured wheelchair passenger back into her wheelchair. The wheelchair passenger crawled to the front door of the LATV, where she was placed on a stretcher and transported to an ambulance.

\section{DISCUSSION}

To our knowledge, this is the first observational study to examine wheelchair instability in LATVs based on in-vehicle video footage of actual events. Our objective was to characterize adverse events involving wheelchair instability related to WTORS disuse and misuse onboard LATVs.

The overall relatively high occurrence (20.3\%) of adverse events (wheelchair-related instabilities) we found could potentially be lowered if the frequency of proper WTORS use is increased. This may be achieved through additional training for LATV operators by transit agencies and through increased wheelchair passenger awareness of the risks associated with improper WTORS use.

\section{Wheelchair Instability Based on Wheelchair Type}

We found that power wheelchair users represented the greatest percentage of wheelchair passengers in fixed-route transit (68.5\%), followed by manual wheelchair users $(24.7 \%)$ and scooter users (6.4\%). This finding is consistent with data published by Buning et al. [5]. Buning et al. surveyed public transit wheelchair passengers $(n=283)$ nationally and found that 63.3 percent used power wheelchairs, 27.9 percent used manual wheelchairs, and 5.9 percent used power scooters.

The results from our study also show that, despite the greater percentage of power wheelchairs used as seats in LATVs, scooters and manual wheelchairs exhibit greater instability during transit (36.8\% and $30.1 \%$, respectively, versus $15.3 \%$ for power wheelchairs). Although the sample size may be limited, these findings may suggest a pattern of wheelchair instability by wheelchair type. All scooters were three-wheeled designs; however, there was no specific pattern in the direction of excursion for scooter instability cases. Scooters have been found to possess a lower center of gravity (CG) than power and manual wheelchairs [12], a characteristic that generally increases stability. There may also be structural features (e.g., three-wheeled designs) that contribute to scooter instability, as well as inaccessible frames that generally do not allow for easy securement using four-point, straptype tiedowns. Scooters may have been less likely to be secured properly given housings that typically enclose their structural frames. Design differences between manual and power wheelchairs may also contribute to differences in wheelchair stability during LATV transit. Compared with power wheelchairs, manual wheelchairs have smaller mass and lower inertia, higher CG [12], and generally less robust brake hardware. When a power wheelchair is turned off, the transmission becomes disengaged, acting as a brake. Manual wheelchair brakes can become misaligned with the rear wheels, making the braking mechanism less effective. Additionally, manual wheelchair brakes are operated by hand and require the application of force to the brake mechanism lever to engage the brake, a task that may be challenging for some manual wheelchair users.

\section{Cases with Minor Instability}

Tiedown usage patterns may be directly related to wheelchair instability. We found that 0 was the most frequent number of tiedowns used for each type of instability, and in only 2 out of 57 cases (3.5\%) were all four tiedowns used to secure the wheelchair (Figure 2). However, given our reliance on video footage, it is not known if tiedowns were applied correctly, using the appropriate securement point on the wheelchair and properly tensioning the tiedowns when used; both could substantially affect the tiedowns' ability to maintain wheelchair securement during LATV transit.

We also found that the most prevalent ORS configuration associated with zero tiedowns across all instability types was the misuse of the lap belt in an attempt to secure the wheelchair. Previously reported by Frost and Bertocci [10], this type of ORS misuse consisted of the lap belt routed around the wheelchair seatback with no use of the shoulder belt. The lap belt tension during such ORS misuse was indeterminable. Since the most frequent number of tiedowns used was zero and misuse of the lap belt was the most prevalent ORS configuration observed for all instability types, it may be concluded that the LATV operators observed in this study are aware of the need to provide wheelchair securement, but are uncertain or are unable to apply the WTORS properly.

An improved understanding as to why operators are not properly implementing WTORSs is needed. Currently, LATV operator training in the proper use of the 
WTORS includes classroom instruction and demonstration, as well as supervised hands-on practice performed in an LATV. Perhaps additional and improved in-depth operator training on proper WTORS implementation could be helpful in avoiding future misuse and disuse of the WTORS.

\section{Cases with Severe Instability}

\section{Case 1: Power Wheelchair Driven into Aisle}

Turning off the power to the wheelchair prior to transit may have prevented the power wheelchair from rotating into the aisle, even if the wheelchair passenger inadvertently struck the control joystick. Also, had all four tiedowns been applied properly (appropriate securement point locations with proper tiedown tension), the power wheelchair would likely not have been able to enter the aisle space.

Although no passengers were injured, the outcome may have been different if passengers were standing in the aisle during transit. This raises the point that proper WTORS application cannot only increase transportation safety for wheelchair passengers, but also increase safe transit for general ridership. Additionally, had the passenger sitting across the aisle from the securement station not attempted to prevent additional wheelchair excursion into the aisle, injuries to both individuals may have occurred.

\section{Case 2: Manual Wheelchair Rotated Laterally into Aisle}

As the manual wheelchair rotated into the aisle during a routine LATV right turn, the wheelchair passenger's ability to restrain himself using his limbs appeared to limit additional excursion into the aisle. Other wheelchair passengers may not have the same level of voluntary muscle control or the ability to restrain themselves as effectively, placing them at an increased risk for injury. Had the wheelchair been properly secured with tiedowns, the lateral wheelchair rotation into the aisle may have been prevented.

\section{Case 3: Power Wheelchair Passenger Ejected from Wheelchair}

The power wheelchair passenger appeared to be using an undersized power wheelchair, equipped with captain seating. This type of seating system in general is not easily adjustable and is typically not designed for persons who may have special seating needs, such as bariat- ric wheelchair users. This illustrates that wheelchair passenger safety on LATVs may not be limited to the issue of proper WTORS application because proper wheelchair prescription (through involvement of qualified therapists) is also important in wheelchair passenger safety. Using a properly applied ORS (lap and/or shoulder belt) would likely have prevented the wheelchair passenger's ejection from her power wheelchair. Finally, without the restraining assistance provided by the nonwheelchair-using passenger, the wheelchair passenger may have incurred additional injuries.

\section{Summary of Cases with Severe Instability}

It is important to note that all three cases of severe instability occurred during normal driving maneuvers. This finding adds to an emerging body of evidence indicating that crash conditions need not be present to subject wheelchair passengers to increased risks while traveling in LATVs. According to Frost and Bertocci, of the wheelchair-related incidents on LATVs that took place when the LATV was moving, 76.7 percent occurred under normal driving conditions, compared with 23.3 percent of incidents that occurred during emergency maneuvers [13]. Wretstrand et al. also found similar results, reporting that most wheelchair user injuries occurred during routine driving maneuvers of paratransit vehicles [14].

Under the broad nondiscrimination provisions in the ADA regulations, transit providers must provide tiedowns but may choose whether or not to mandate their use. However, transit providers may not mandate the use of lap and shoulder belts by wheelchair users unless they mandate this use by all passengers [9]. As a result, wide disparities among transit agency WTORS policies have been documented [5-6]. Buning et al. found that while the majority (66.7\%) of transit providers surveyed required tiedown use for transporting wheelchair passengers, only 25.6 percent of those providers also required ORS use, and 69.5 percent made ORS use optional [5]. Almost 18 percent (17.9\%) of transit providers reported optional wheelchair securement, and of those, 90.9 percent have policies with optional ORS use for wheelchair passengers. Our findings suggest that proper use of the WTORS on LATVs may reduce the number of wheelchair-related adverse events. Increasing the uniformity of transit agency WTORS policies may also increase proper use of the WTORS, thus reducing wheelchair-related adverse events on LATVs. 
Regarding use of four-point strap-type tiedown WTORSs on LATVs, confusion is also evident on the part of wheelchair passengers [5,15]. With regard to requesting securement, Buning et al. found that 39 percent of wheelchair passengers never asked to be secured, compared with 36.6 percent who routinely asked to be secured [5]. Increased awareness regarding the importance of proper WTORS use on the part of wheelchair passengers may lead to increased compliance with transit agency policies regarding WTORS usage. Additionally, this might encourage some wheelchair passengers to play a more active role in responsibility for their safety by requesting WTORS and directing its proper use.

As indicated herein, challenges exist with the use of four-point strap-type tiedown WTORS to secure wheelchair passengers on LATVs. Thus, alternative strategies for wheelchair securement or retention, such as autodocking systems and rear-facing wheelchair passenger stations, are being explored [16-17]. Autodocking systems use hardware that interfaces the wheelchair directly with the docking system installed in the LATV. Rear-facing wheelchair passenger stations require passengers to back their wheelchair against a vehicle-mounted, padded restraint that fits in close proximity to the passenger's head and back to prevent against forward wheelchair excursions. A vertical stanchion may be present, or a horizontal side barrier may fold down to prevent lateral wheelchair excursion. These alternative systems may increase wheelchair retention or securement, since they can be used independently or with minimal LATV operator involvement. National and international standards (Society of Automotive Engineers standard J2249 [8], International Organization for Standardization [ISO] standard 10542 [18], and ISO standard 10865-2 [19]) addressing these systems allow for design flexibility, providing an opportunity for alternative means to safely secure wheelchairs and restrain wheelchair passengers. While these alternatives provide benefits, there are drawbacks, such as the need for additional hardware on wheelchairs to use the autodocking system (affecting ground clearance, weight, and in some cases, overall wheelchair dimensions [17]) and difficulties associated with facing rearward during transit. Additionally, the safety of rear-facing passenger systems has yet to be thoroughly investigated.

\section{Limitations}

The WoFT data are based on video surveillance footage from only one transit agency from a major metropolitan area in a Midwestern geographical area. Wheelchair-related data from other transit agencies in other regions of the country may produce different results. The video data reviewed for this study was of relatively low resolution $(640 \times 480$ pixels) and low frequency $(30 \mathrm{~Hz})$. Because of low-frequency and -resolution video, the categorization of minor and severe instability was somewhat subjective; others may have included or excluded different events. Higher resolution and higher frequency video data may provide improved details, including quantifiable wheelchair and/or passenger excursions. Since LATVs were equipped with varying numbers of cameras (4 to 6), limited view angles were available in some cases. In these cases, additional cameras may have provided more detailed information. Our assessment of video footage only determined whether the WTORS were used, but did not allow us to determine WTORS tension or angles and the exact location of securement on wheelchair. Additionally, the transit agency's practices include random assignment of LATVs to routes on a daily basis; the majority of LATV operators are also randomly assigned routes for each work shift. Given these practices and the relatively low resolution of the video images, we made no effort to identify or filter videos for wheelchair passengers or LATV operators who may have been recorded more than once. As a result, it is possible that the data contain multiple trips of one or more wheelchair passengers and multiple trips involving one or more LATV operators. Finally, we did not include testimonies from involved parties; the LATV operator, wheelchair passenger, and other passengers may have been able to provide supplementary information to aid in better understanding the underlying causes of the adverse events.

\section{CONCLUSIONS}

The identified adverse events occurred during normal driving. The vast majority involved minor instability, and only a small number were severe instability cases. When normalized by the number of trips for each wheelchair type, scooters had the highest proportion of instability, followed by manual wheelchairs and power wheelchairs.

The most common direction of wheelchair excursion was a combination of fore/aft and lateral excursions, followed by fore/aft excursion only, lateral excursion only, and other excursion types. For adverse events, the most common number of wheelchair tiedowns used was zero, while the most common ORS configuration was the 
misuse of the lap belt to attempt to secure the wheelchair and not to restrain the wheelchair passenger.

The three cases of severe instability suggested that wheelchair-related adverse events could occur during normal LATV driving maneuvers. Applying wheelchair brakes or turning off power wheelchairs, using all four tiedowns correctly, and using the lap and shoulder belt properly may have prevented these adverse events. Nonwheelchair-using passengers may also be at increased risk of injury if a wheelchair-related adverse event occurs during LATV transit.

\section{ACKNOWLEDGMENTS}

\section{Author Contributions:}

Data collection and analysis: Z. Salipur, K. Frost, G. Bertocci. Drafting of manuscript: Z. Salipur, K. Frost, G. Bertocci.

Study design: K. Frost, G. Bertocci.

Secured funding: K. Frost, G. Bertocci.

Financial Contributions: The authors have declared that no competing interests exist.

Funding/Support: This material was based on work supported by the National Institute on Disability and Rehabilitation Research (NIDRR) through the Rehabilitation Engineering Research Center on Wheelchair Transportation (grant H133E060064) and the Switzer Fellowship program (grant H133F100032).

Institutional Review: Approval to conduct this study was obtained from the University of Louisville Institutional Review Board.

Disclaimer: The opinions expressed herein are those of the authors and do not necessarily reflect those of the NIDRR.

\section{REFERENCES}

1. Shaw G. Wheelchair rider risk in motor vehicles: a technical note. J Rehabil Res Dev. 2000;37(1):89-100. [PMID:10847576]

2. Shaw G, Gillispie T. Appropriate protection for wheelchair riders on public transit buses. J Rehabil Res Dev. 2003; 40(4):309-19. [PMID:15074442] http://dx.doi.org/10.1682/JRRD.2003.07.0309

3. Shaw G. Investigation of large transit vehicle accidents and establishing appropriate protection for wheelchair riders. J Rehabil Res Dev. 2008;45(1):85-108. [PMID:18566928] http://dx.doi.org/10.1682/JRRD.2007.03.0045

4. National Highway Transportation Safety Administration. Research note: wheelchair users injuries and deaths associated with motor vehicle related incidents. Washington (DC): U.S. Department of Transportation; 1997.

5. Buning ME, Getchell CA, Bertocci GE, Fitzgerald SG. Riding a bus while seated in a wheelchair: a pilot study of attitudes and behavior regarding safety practices. Assist Technol. 2007;19(4):166-79. [PMID:18335706] http://dx.doi.org/10.1080/10400435.2007.10131874

6. Songer TJ, Fitzgerald SG, Rotko K. The injury risk to wheelchair occupants using motor vehicle transportation. Annu Proc Assoc Adv Automot Med. 2004;48:115-29. [PMID:15319121]

7. Americans with Disabilities Act (ADA) accessibility specifications for transportation vehicles, ADA, 49 CFR part 38. Fed Regist. 1990.

8. Society of Automotive Engineers. SAE J2249: Wheelchair tiedown and occupant restraint systems for use in motor vehicles. Warrendale (PA): Society of Automotive Engineers; 1996.

9. Americans with Disabilities Act (ADA) transportation services for individuals with disabilities, ADA, 49 CFR part 37. Fed Regist. 1990.

10. Frost K, Bertocci GE. Wheelchair securement and occupant restraint practices in large accessible transit vehicles. Proceedings of the Annual Rehabilitation Engineering Society of North America Conference; 2009 Jun; New Orleans, LA.

11. Wolf PJ, van Roosmalen L, Bertocci GE. Wheelchair tiedown and occupant restraint system issues in the real world and the virtual world: combining qualitative and quantitative research approaches. Assist Technol. 2007; 19(4):18896, quiz 197-98. [PMID:18335708] http://dx.doi.org/10.1080/10400435.2007.10131876

12. Bertocci G, Karg P, Hobson D. Wheeled mobility device database for transportation safety research and standards. Assist Technol. 1997;9(2):102-15. [PMID:10177448] http://dx.doi.org/10.1080/10400435.1997.10132302

13. Frost KL, Bertocci GE. Retrospective review of adverse incidents involving passengers seated in wheeled mobility devices while traveling in large accessible transit vehicles. Med Eng Phys. 2010;32(3):230-36. [PMID:19395304] http://dx.doi.org/10.1016/j.medengphy.2009.01.004

14. Wretstrand A, Petzäll J, Ståhl A. Safety as perceived by wheelchair-seated passengers in special transportation services. Accid Anal Prev. 2004;36(1):3-11. [PMID:14572821] http://dx.doi.org/10.1016/S0001-4575(02)00108-2

15. Foreman C, Hardin J. The challenges of wheelchair securement: searching for solutions. 2002 American Public Transportation Association Bus \& Paratransit Conference; 2002 May 5-9; Minneapolis, MN.

16. Van Roosmalen L, Karg P, Hobson D, Turkovich M, Porach E. User evaluation of three wheelchair securement systems in large accessible transit vehicles. J Rehabil Res Dev. 2011;48(7):823-38. [PMID:21938667] http://dx.doi.org/10.1682/JRRD.2010.07.0126

17. Hobson DA, van Roosmalen L. Towards the next generation of wheelchair securement-development of a demonstration UDIG-compatible wheelchair docking device. 
Assist Technol. 2007;19(4):210-22. [PMID:18335710]

http://dx.doi.org/10.1080/10400435.2007.10131878

18. International Organization for Standardization. ISO 10542: Technical systems and aids for disabled or handicapped persons-Wheelchair tiedown and occupant-restraint systems. Geneva (Switzerland): International Organization for Standardization; 2001.

19. International Organization for Standardization. ISO 108651: Assistive products for persons with disability-Wheelchair containment and occupant retention systems for motor vehicles designed for use by both sitting and standing passengers-Part 1: Systems for rearward facing wheelchair-seated passengers. Geneva (Switzerland): International Organization for Standardization; 2011.

Submitted for publication June 2, 2011. Accepted in revised form November 4, 2011.
This article and any supplementary material should be cited as follows:

Salipur Z, Frost K, Bertocci G. Investigation of wheelchair instability during transport in large accessible transit vehicles. J Rehabil Res Dev. 2012;49(6):935-48.

http://doi.dx.org/10.1682/JRRD.2011.06.0098

ResearcherID: Zdravko Salipur, MEng: D-8898-2012; Karen Frost, PhD: D-9246-2012; Gina Bertocci, PhD, PE: D-9241-2012

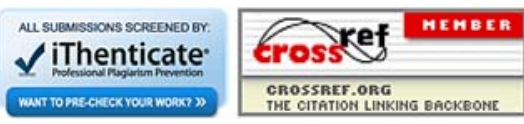

